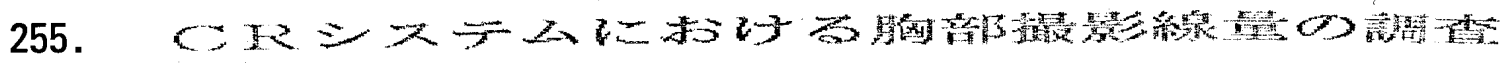

\title{
A survey of radiographic dose for chest radiography in CR system
}

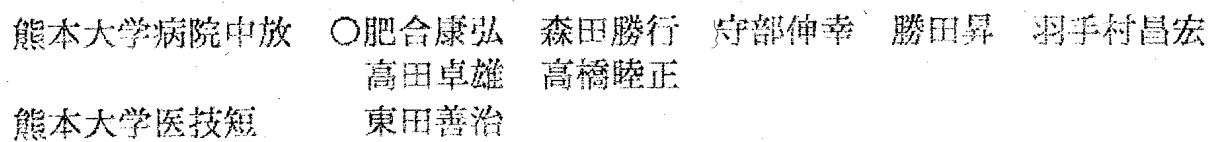

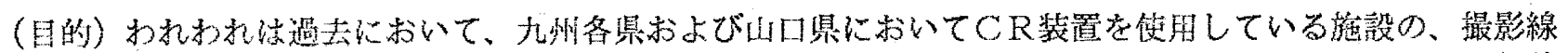

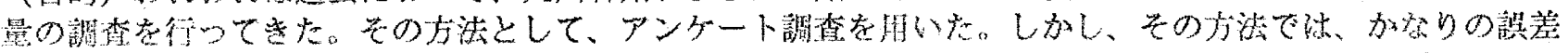

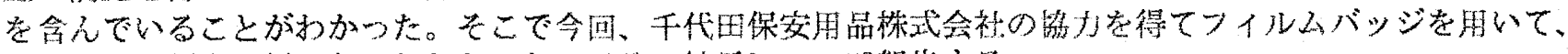

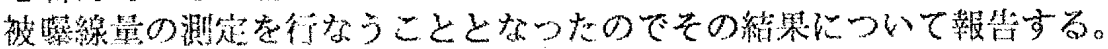

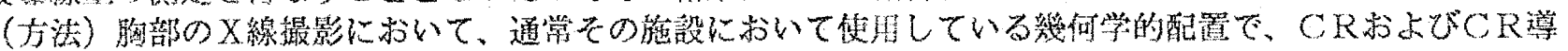

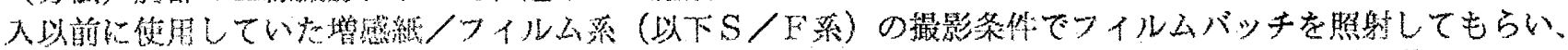

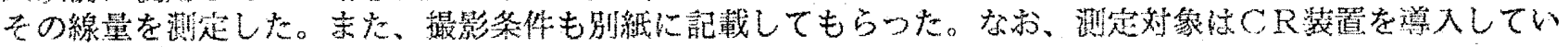

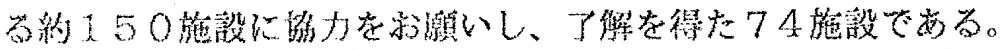

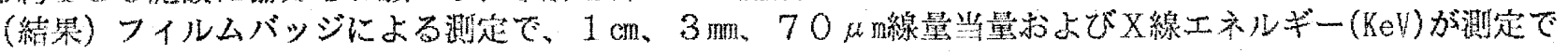

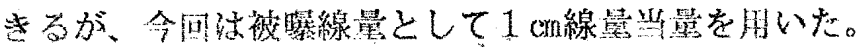

F j.

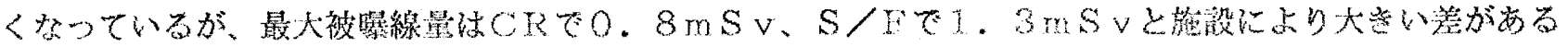
ことがかが。

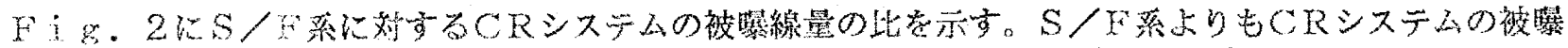

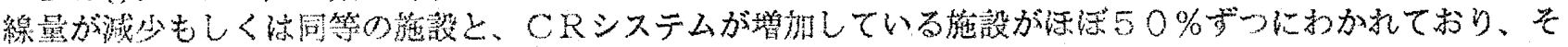

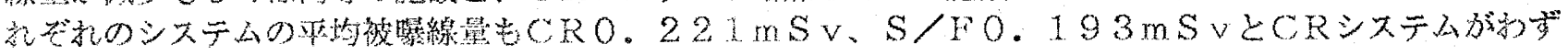

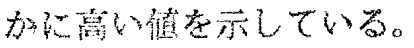

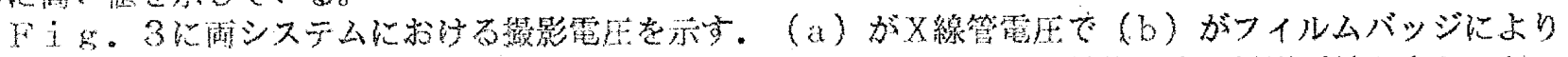

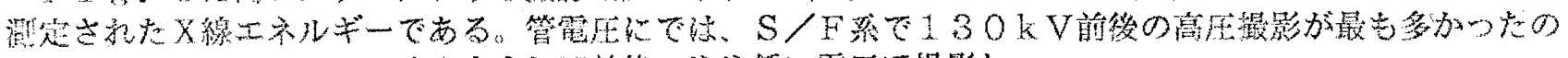

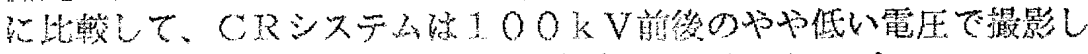

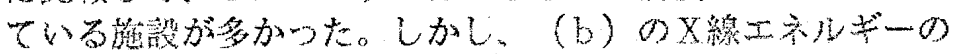

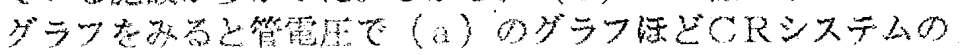

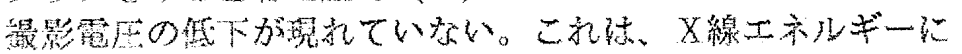

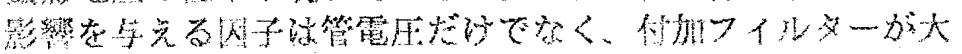
语く影噼しているた好と考光る。

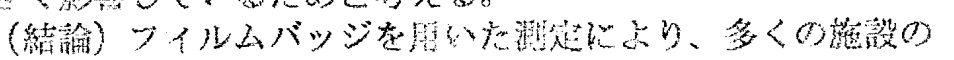

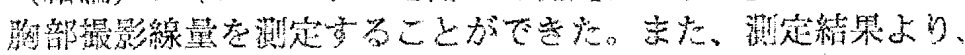

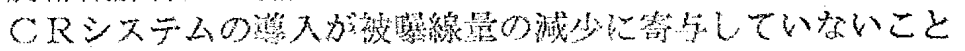

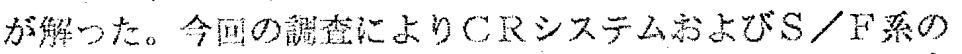

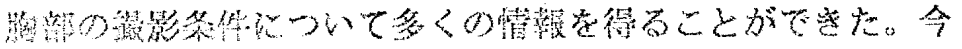

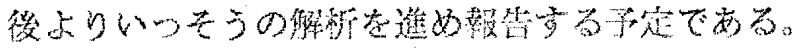
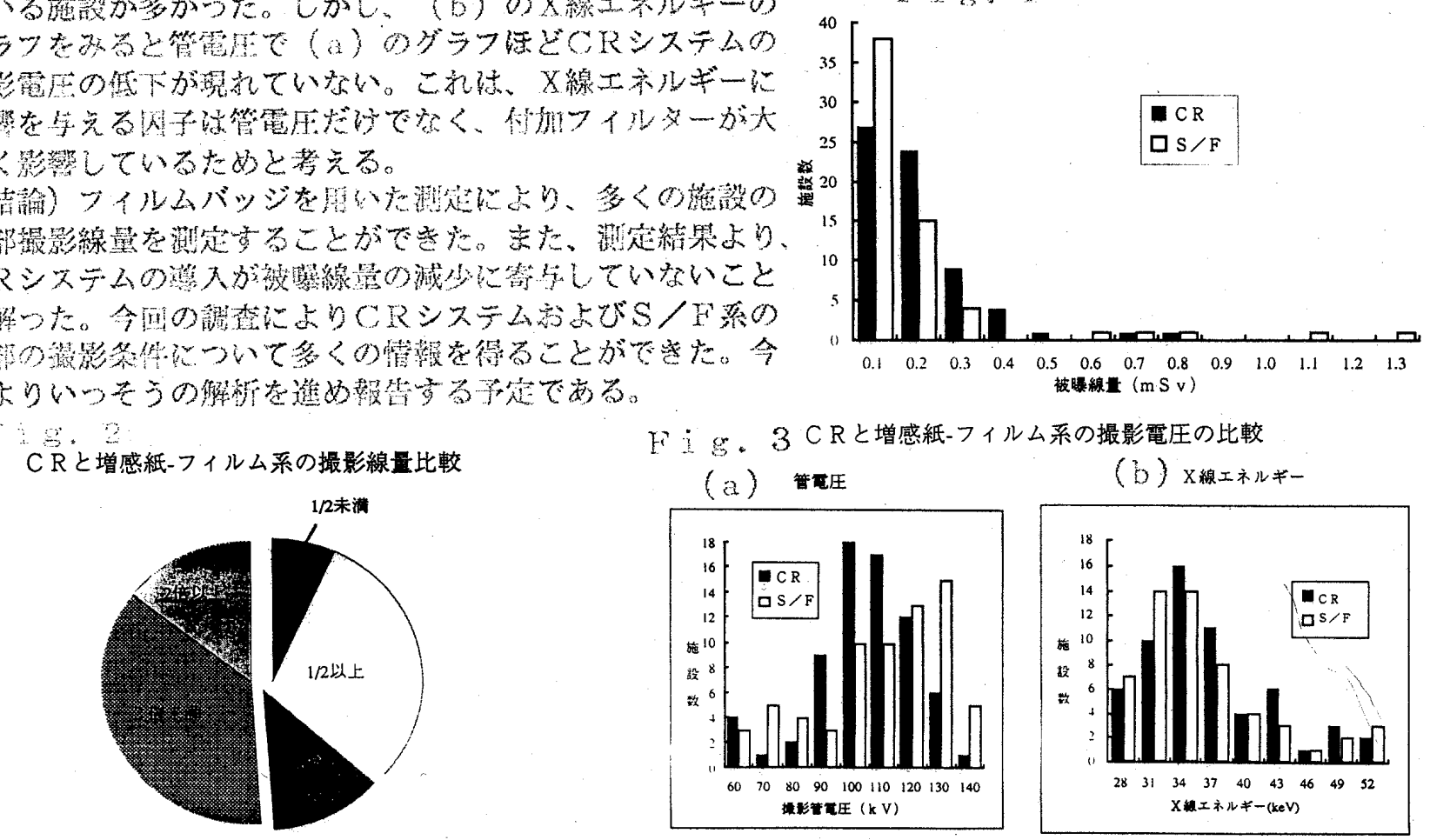

Fig. 3 C R と増感紙-フィルム系の撮影電质の比較

(a) 䉕酯厌

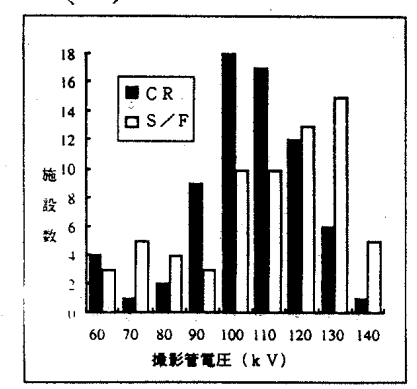

(b) X線エネルギー

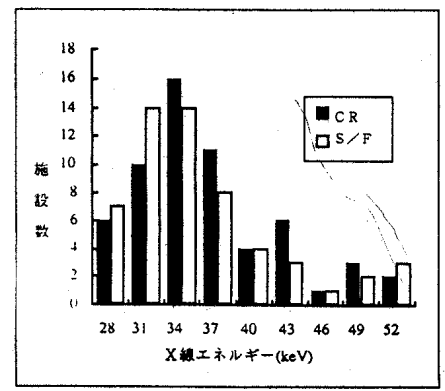

